\title{
Ultraviolet Stability of Crosslinked Polycaprolactam Systems
}

\author{
Stephen D. Bruck ${ }^{*}$
}

(August 2, 1962)

\begin{abstract}
The relative ultraviolet stability of four chemically modified polycaprolactam (Nylon-6) systems is discussed: methylmethoxylated fibers and three other fibers having methylene, disulfide, and alkylene sulfide crosslinks, respectively. The ultraviolet degradation of these systems is studied by means of a sensitive analytical technique in which the methylene $\left(-\mathrm{CH}_{2}-\right)$ groups remaining in the chemically modified fibers after irradiation are converted to formaldehyde; the liberated formaldehyde is then reacted with chromotropic acid to give a colored product, the absorbancy of which can be determined spectrophotometrically. The results indicate that the data can be expressed by first order rate equations from which the rate constants may be calculated. The scission of the crosslinks is accompanied by a decrease in the internal orientation of the networks as shown by X-ray diffraction photographs.
\end{abstract}

\section{Introduction}

Previous communications from this laboratory [1 to 4$]^{1}$ described macroscopic deformations such as helical coiling and self-crimping of polycaprolactam (Nylon-6) fibers as a result of heterogeneous crosslinking in the swollen state. Among other fundamental properties of these crosslinked systems, their stability under ultraviolet radiation is of considerable interest. By studying such selected model systems, it might be possible to predict the behavior of others. It is the object of this paper to evaluate the relative ultraviolet stability of fibers having methylene, disulfide, and alkylene sulfide crosslinks, respectively, and also fibers with methylmethoxyl groups on the amide nitrogen atoms.

\section{Discussion}

The following structures are involved in this study:

I.

$$
\mathrm{O}=\underset{\mathrm{C}}{\mathrm{N}} \mathrm{i}-\mathrm{CH}_{2}-\mathrm{O}-\mathrm{CH}_{3}
$$

II.

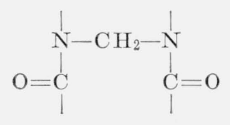

III.

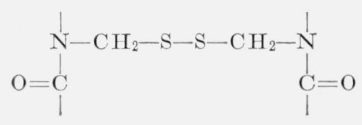

IV.

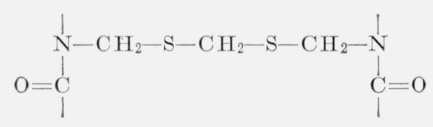

*Present address: Applied Physics Laboratory, The Johns Hopkins University

8621 Georgia Avenue, Silver Spring, Md.
1 Figures in brackets indicate the literature references at the end of this paper.
Structure (I) is a precursor in the preparation of the sulfur containing crosslinked structures (III, IV). The crosslinked unit (II) incorporates only one methylene group between the adjacent amide nitrogen atoms of two polymer chains; system (III) has a disulfide type crosslink and includes two methylene groups; finally structure (IV) has three methylene groups, one of which is interposed between two sulfur atoms. By such systematic variation of the type and length of crosslinks, it should be possible to evaluate their comparative ultraviolet stability and arrive at knetic deductions.

In order to study the ultraviolet degradation of these systems, use was made of a sensitive analytical technique described in detail elsewhere $[5,6]$. In this method, the methylene $\left(-\mathrm{CH}_{2}-\right)$ groups in structures (I to IV) are hydrolyzed with sulfuric acid to yield one equivalent of formaldehyde per equivalent of methylene group. The formaldehyde so formed is then reacted with chromotropic acid (1,8,-dihydroxynaphthalene-3,6, disulfonic acid), and the absorbancy $\left(\log I_{0} / I\right.$.) of the resulting reaction product is subsequently determined at $570 \mathrm{~m} \mu$ with a spectrophotometer. From the formaldehyde anaylsis it is possible to estimate the number of equivalents of crosslinks per $10^{6} \mathrm{~g}$ of polymer. Although it was shown previously $[7,8]$ that in the case of a well-defined, fairly uniform crosslinked fiber the number of equivalents of crosslinks may be calculated from equilibrium swelling measurements, such an approach cannot be entirely relied upon when the crosslinking density across the fiber's cross section is nonuniform, as is the case with the systems having disulfide and alkylene sulfide type crosslinks $[1,2]$. Futhermore, the ultraviolet irradiation may cause additional crosslinking not originally present in the system which, by participation in the swelling process, would obscure the calculations.

In the present work, two General Electric G25'T8 germicidal, low-pressure mercury lamps were used. According to G.E. data, about 60 percent of the 
input energy is transformed into a predominant wavelength of $2537 \mathrm{~A}$, of which the special glass envelope transmits about 74 percent, or close to half of the total energy input. Thus, this type of lamp is a convenient source for nearly monochromatic ultraviolet radiation. Of the remainder of the energy, 2 percent is transmitted into visible light, and 48 percent is transformed into heat. Due to the special glass envelope, no energy was transmitted below $2000 \mathrm{~A}$. The fibers were mounted on a specially designed stainless-steel holder in the manner illustrated by figure 1 . The assembly was

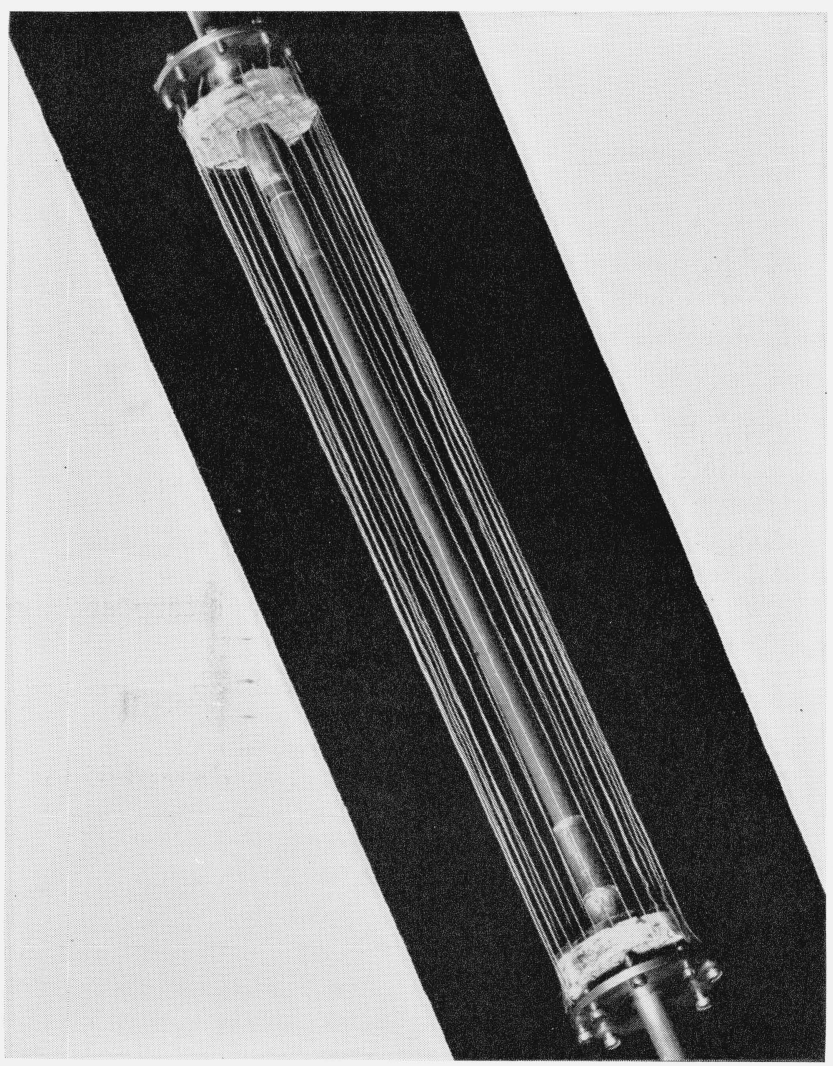

Figure 1. Sample holder.

then placed inside a quartz tube and slowly rotated in front of the mercury lamps by means of an electrically operated magnetic coupling. The lamps were placed approximately 2 in. away from the quartz tube and opposite each other.

During the irradiation, the pressure inside the apparatus was kept at $10^{-4}$ to $10^{-5} \mathrm{~mm}$ of $\mathrm{Hg}$ by means of an oil-diffusion and mechanical pumping system. The G25T8 mercury lamps permitted the use of samples large enough for subsequent analytical work. The average intensity of the illumination at the detector was measured by suspending a vacuum thermopile inside the quartz sample holder tube, and was found to be $6,800 \mu \mathrm{w} / \mathrm{cm}^{2}$ or $6.80 \times 10^{4}$ $\mathrm{ergs} / \mathrm{cm}^{2}$-sec. It was also established that the intensity of the radiation along the axis of the lamp was uniform within 10 percent. Furthermore, the decrease in intensity of the lamps during the irradia- tion process was negligible and the temperature within the sample tube did not rise above $40{ }^{\circ} \mathrm{C}$.

No attempt was made to determine quantum yields in the present work due to the fibrous nature of the samples which gives rise to considerable scattering of radiation that is difficult to measure. The fiber samples were irradiated in vacuum for up to 50 $\mathrm{hr}$, treated for $0.5 \mathrm{hr}$ in distilled water at $90{ }^{\circ} \mathrm{C}$ to remove the degradation products, dried, and then subjected to formaldehyde $[5,6]$ and methoxyl analyses [9]. Thus, the evolved quantities of formaldehyde represent the remaining (nonphotolysed) groups in structures I to IV. The results are summarized in table 1. In all cases there is a decrease in the methylene groups that are part of the crosslinks and also in the methylene groups that are part of the methylmethoxylated fiber, as indicated by the drop in formaldehyde concentration.

TABLE 1. Kinetic data for ultraviolet degradation of chemically modified polycaprolactam fibers

\begin{tabular}{|c|c|c|c|c|c|c|}
\hline $\begin{array}{c}\text { Sample } \\
\text { No. }\end{array}$ & $\begin{array}{c}\text { Type of } \\
\text { modifica- } \\
\text { tion a }\end{array}$ & $\begin{array}{c}\text { Irradia- } \\
\text { tion } \\
\text { time }\end{array}$ & $\begin{array}{l}\text { Sample } \\
\text { weight }\end{array}$ & $\log I_{0} / I$ & $\% \mathrm{CH}_{2} \mathrm{O}$ & $\%-\mathrm{OCH}_{3} \mathrm{~b}$ \\
\hline $\begin{array}{l}1 \\
2 \\
3 \\
4 \\
5 \\
6 \\
7 \\
8 \\
9\end{array}$ & $\begin{array}{l}\text { A } \\
\text { A } \\
\text { A } \\
\text { A } \\
\text { A } \\
\text { A } \\
\text { A } \\
\text { A } \\
\text { A }\end{array}$ & $\begin{array}{c}h r \\
0 \\
2 \\
4 \\
6 \\
8 \\
12 \\
16.3 \\
20 \\
30\end{array}$ & $\begin{array}{c}m g \\
24.40 \\
25.45 \\
22.82 \\
20.90 \\
22.90 \\
20.45 \\
25.95 \\
19.87 \\
25.10\end{array}$ & $\begin{array}{r}0.262 \\
.236 \\
.182 \\
.146 \\
.148 \\
.125 \\
.118 \\
.098 \\
.105\end{array}$ & $\begin{array}{l}4.0 \pm 0.1 \\
2.5 \\
3.0 \\
2.6 \\
2.4 \\
2.3 \\
1.6 \\
1.8 \\
1.5\end{array}$ & $\begin{array}{l}3.0 \pm 0.1 \\
2.4 \\
2.6 \\
2.3 \\
2.5 \\
2.1 \\
2.0 \\
1.9 \\
1.7\end{array}$ \\
\hline $\begin{array}{l}1 \\
2 \\
3 \\
4 \\
5 \\
6 \\
7 \\
8 \\
9\end{array}$ & $\begin{array}{l}\mathrm{B} \\
\mathrm{B} \\
\mathrm{B} \\
\mathrm{B} \\
\mathrm{B} \\
\mathrm{B} \\
\mathrm{B} \\
\mathrm{B} \\
\mathrm{B}\end{array}$ & $\begin{array}{c}0 \\
2 \\
4 \\
6 \\
8.5 \\
15 \\
20 \\
30 \\
40\end{array}$ & $\begin{array}{l}16.60 \\
16.92 \\
17.29 \\
16.06 \\
16.85 \\
16.23 \\
15.85 \\
16.59 \\
15.53\end{array}$ & $\begin{array}{l}.251 \\
.210 \\
.179 \\
.143 \\
.160 \\
.113 \\
.103 \\
.089 \\
.082\end{array}$ & $\begin{array}{l}5.6 \pm 0.1 \\
4.6 \\
3.8 \\
3.3 \\
3.5 \\
2.5 \\
2.3 \\
2.0 \\
1.9\end{array}$ & \\
\hline $\begin{array}{l}1 \\
2 \\
3 \\
4 \\
5 \\
6 \\
7 \\
7 \\
8 \\
9\end{array}$ & $\begin{array}{l}\mathrm{C} \\
\mathrm{C} \\
\mathrm{C} \\
\mathrm{C} \\
\mathrm{C} \\
\mathrm{C} \\
\mathrm{C} \\
\mathrm{C} \\
\mathrm{C}\end{array}$ & $\begin{array}{l}0 \\
2.5 \\
4 \\
6.1 \\
8 \\
12 \\
16 \\
20 \\
30\end{array}$ & $\begin{array}{l}24.25 \\
17.24 \\
16.83 \\
23.73 \\
23.32 \\
22.06 \\
17.44 \\
19.03 \\
16.72\end{array}$ & $\begin{array}{l}.161 \\
.097 \\
.092 \\
.132 \\
.109 \\
.091 \\
.069 \\
.068 \\
.051\end{array}$ & $\begin{array}{l}2.4 \pm 0.1 \\
2.0 \\
2.0 \\
2.0 \\
1.7 \\
1.5 \\
1.4 \\
1.3 \\
1.0\end{array}$ & \\
\hline $\begin{array}{l}1 \\
2 \\
3 \\
4 \\
5 \\
6 \\
7 \\
8 \\
9\end{array}$ & $\begin{array}{l}\mathrm{D} \\
\mathrm{D} \\
\mathrm{D} \\
\mathrm{D} \\
\mathrm{D} \\
\mathrm{D} \\
\mathrm{D} \\
\mathrm{D} \\
\mathrm{D}\end{array}$ & $\begin{array}{r}0 \\
2 \\
4 \\
6 \\
8 \\
12 \\
16 \\
20 \\
30\end{array}$ & $\begin{array}{l}20.94 \\
18.52 \\
23.39 \\
31.14 \\
20.64 \\
20.76 \\
30.03 \\
23.34 \\
22.95\end{array}$ & $\begin{array}{l}.150 \\
.114 \\
.130 \\
.148 \\
.106 \\
.097 \\
.101 \\
.078 \\
.088\end{array}$ & $\begin{array}{l}2.6 \pm 0.1 \\
2.3 \\
2.0 \\
1.8 \\
1.9 \\
1.7 \\
1.2 \\
1.2 \\
1.3\end{array}$ & \\
\hline
\end{tabular}

$$
\text { D. }
$$

b Modified Clark apparatus used. Procedure: A. Steyermark, Quantitative Organic Microanalysis, p. 431 (Academic Press Inc., New York, 1961).

An uncrosslinked but irradiated control sample of polycaprolactam gave no positive test for formaldehyde but showed an increase in inherent viscosity, as seen in table 2. Small gel particles were observed in 
TABLE 2. Inherent viscosity of uncrosslinked (control) samples of polycaprolactam fibers

\begin{tabular}{c|c}
\hline \hline Time of irradiation & $\begin{array}{c}\text { Inherent viscosity } \\
\left(25^{\circ} \mathrm{C} \pm 0.1\right) \\
90 \% \text { formic acid }\end{array}$ \\
\hline$h r$ & \\
0 & 1.005 \\
2 & 1.145 \\
12 & 1.230 \\
$20 \mathrm{a}$ & 1.400 \\
\hline
\end{tabular}

a Filtered to remove gel particles.

the uncrosslinked control samples that had been irradiated for $20 \mathrm{hr}$, indicating the presence of radiation-induced crosslinks. This type of crosslinks differs from the chemically implanted ones as the former type represents actual "point-contacts" between two polymer chains as the result of recombination of free radicals, whereas the chemically implanted crosslinks have predetermined chemical composition and length.

The fact that chemically implanted crosslinks are broken by ultraviolet irradiation is also seen from equilibrium swelling measurements that were carried out by a photomicrographic technique described elsewhere $[7,8]$.

Figure 2 is a plot of the equilibrium volume swelling ratio, $q_{m}$ (swelling agent: $m$-cresol) versus irradiation time for caprolactam fibers having methylene $\left(-\mathrm{CH}_{2}-\right)$ crosslinks. The symbol $q_{m}=V / V_{0}$, where $V=$ the volume of the crosslinked network at equilibrium swelling, and $V_{0}=$ the volume of the network before swelling. As figure 2 shows, the

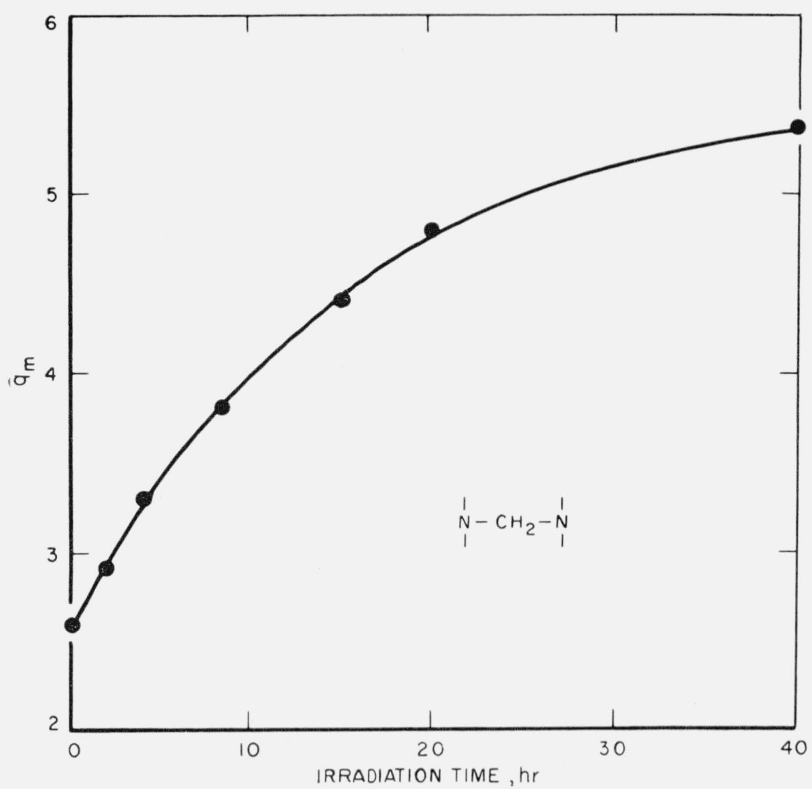

Figure 2. Variation of equilibrium volume swelling ratio $\left(q_{m}\right)$ with irradiation time for methylene-crosslinked polycaprolactam fibers. ultraviolet irradiation results in an increase in the $q_{m}$ values, indicating a decrease in the crosslinking density. The sharp leveling off at approximately $20 \mathrm{hr}$ of irradiation is most likely due to the appearance of radiation-induced crosslinking, the existence of which has already been shown by intrinsic viscosity measurements. In view of the fact that both the radiation-induced crosslinks and the chemically introduced crosslinks contribute to the swelling process, and because it is not possible to separate each of these variables, the equilibrium swelling measurements were not used in the calculation of the crosslinking density. Instead, the number of equivalents of chemically introduced crosslinks broken during the irradiation process was obtained from chemical analyses, as will be discussed below.

\section{Kinetic Analysis of the Data}

For the kinetic analysis of the data the logarithm of the percent formaldehyde was plotted against irradiation time. Figure 3 illustrates the data for the degradation of the methylmethoxyl groups in chemically modified polycaprolactam fibers when subjected to ultraviolet irradiation at $2537 \mathrm{~A}$. If the methylmethoxylation process were free of side reactions, only one methylmethoxyl group would be attached to the amide nitrogen atom, which should yield one mole of formaldehyde (from the $-\mathrm{CH}_{2}-$ group) and one mole of methoxyl ( $-\mathrm{O}-\mathrm{CH}_{3}$ group). However, the reaction conditions for the methylmethoxylation process $[2,10]$ do not entirely eliminate the formation of small amounts of polymethylol groups. The degradation of such groups will result in the evolution of formaldehyde but no methoxyl groups. Thus, the photolysis of the polymethylol and methylmethoxyl groups could be assumed to proceed according to two independent reactions as follows:

$$
\mathrm{O}=\underset{\mathrm{C}}{\stackrel{\mathrm{C}}{\mathrm{N}}-\left(\mathrm{CH}_{2} \mathrm{O}\right)_{\mathrm{n}}-\mathrm{OH} \underset{k_{1}}{\mathrm{U} \cdot \mathrm{V}} \text { degradation products }}
$$

where $n=1$ to 25

$$
\mathrm{O}=\underset{\mathrm{C}}{\stackrel{\mathrm{C}}{\mathrm{N}}-\mathrm{CH}_{2}-\mathrm{O}-\mathrm{CH}_{3} \underset{k_{2}}{\stackrel{\mathrm{U} . \mathrm{V}}{\longrightarrow}} \text { degradation products }}
$$

From Figure 3 it is noted that the unirradiated samples yielded approximately 4 percent (by weight) formaldehyde and 3 percent (by weight) methoxyl groups. However, after an irradiation period of approximately $5 \mathrm{hr}$, the samples continued to yield practically identical quantities of formaldehyde and methoxyl groups by weight. (It should be noted that the weight percent of both formaldehyde $(M . W .=30)$ and methoxyl groups $(M . W .=31)$ have very nearly the same relation to the mole percent of these materials.) An analysis of the data indicates the existence of two, simultaneous, but independent first order reactions (I and II, above), the effect of which may be mathematically expressed as follows 


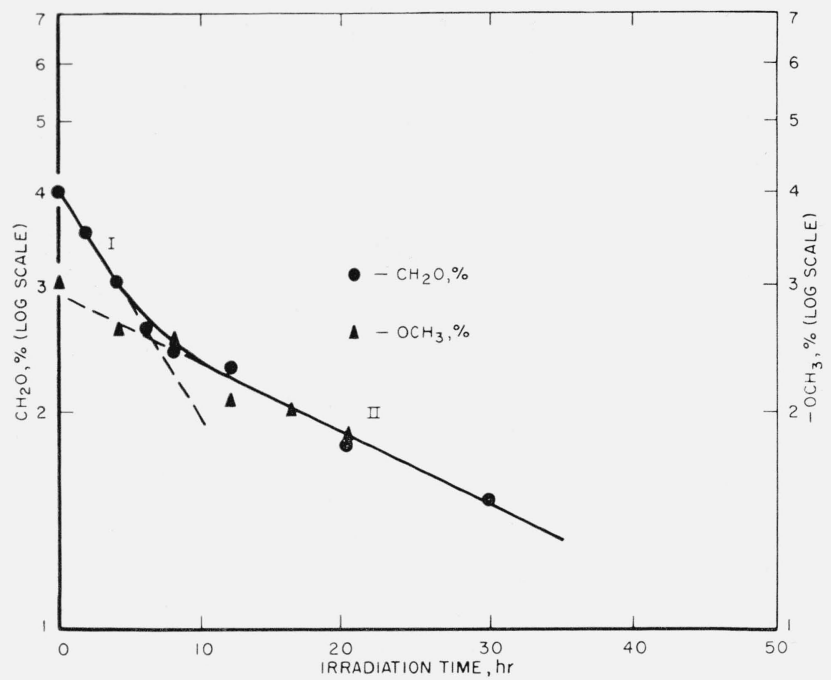

Figure 3. Logarithmic plot of the ultraviolet degradation of methoxymethylated polycaprolactam fibers.

provided the absorption is a small fraction of the incident light:

$$
\begin{array}{ll}
\text { I. } & \frac{-d \mathbf{C}_{\mathrm{I}}}{d t}=k_{1} \mathrm{C}_{\mathrm{I}} \\
\text { II. } & \frac{-d \mathrm{C}_{\mathrm{II}}}{d t}=k_{2} \mathrm{C}_{\mathrm{II}}
\end{array}
$$

and,

I.

$$
\mathrm{C}_{\mathrm{I}}=A \exp \left(-k_{1} t\right)
$$

II.

$$
\mathrm{C}_{\mathrm{II}}=B \exp \left(-k_{2} t\right)
$$

where,

$\mathrm{C}_{\mathrm{I}}=$ concentration of formaldehyde evolved by acid hydrolysis of the nonphotolysed polymethylol 6roups remaining in the fiber after irradiation. $\mathrm{C}_{\mathrm{II}}=$ concentration of formaldehyde evolved by acid hydrolysis of the nonphotolysed methylmethoxyl groups remaining in the fiber after irradiation.

$k_{1}$ and $k_{2}=$ respective rate constants $\left(\mathrm{hr}^{-1}\right)$

$A$ and $B=$ constants

$t=$ time of irradiation $(\mathrm{hr})$.

Thus:

where

$$
\mathrm{C}=\mathrm{C}_{\mathrm{I}}+\mathrm{C}_{\mathrm{II}}=A e^{-k_{1} t}+B e^{-k_{2} t}
$$

\section{$\mathrm{C}=$ total concentration of evolved formaldehyde.}

From the above expression, $k_{1}=0.18 \mathrm{hr}^{-1}$, and $k_{2}=0.01 \mathrm{hr}^{-1}$, indicating that reaction $\mathrm{I}$ is much faster than reaction II.

A similar approach can be extended to the polycaprolactam system having methylene $\left(-\mathrm{CH}_{2}-\right)$ crosslinks. Although this type of crosslink is predominant in the fiber, the nature of the chemical reaction

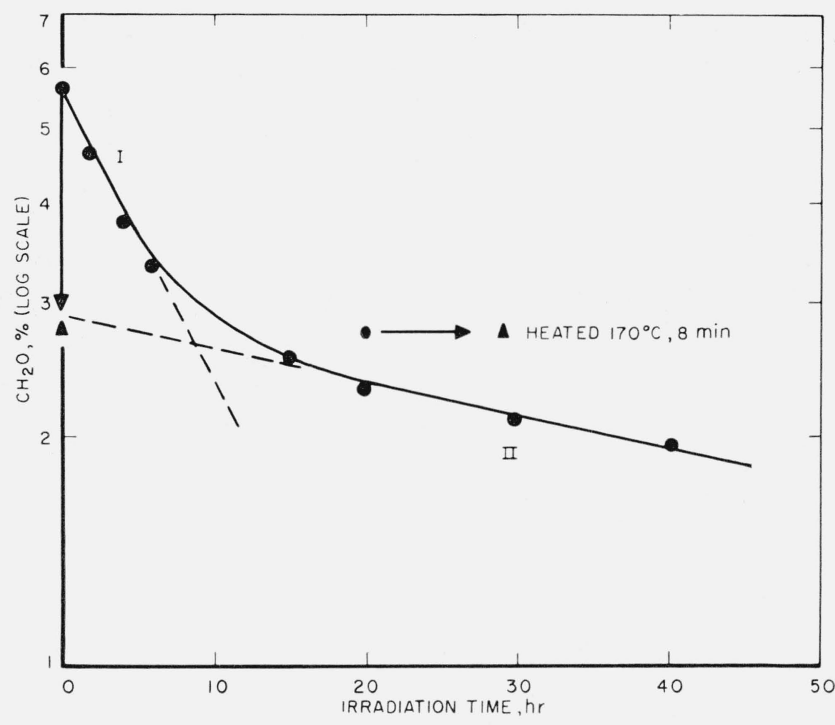

FIgure 4. Logarithmic plot of the ultraviolet degradation of methylene-crosslinked polycaprolactam fibers.

process [11] also gives rise to long polyformaldehyde crosslinks. Even relatively few of these crosslinks will result in the liberation of large quantities of formaldehyde upon irradiation. Furthermore, the polyformaldehyde type crosslinks are known to be heat-sensitive and can be converted to short methylene crosslinks upon heating. Advantage was taken of this property by heating the original, unirradiated, crosslinked sample at $170{ }^{\circ} \mathrm{C}$ for $8 \mathrm{~min}$. in a vapor bath, whereupon its original formaldehyde content of 5.6 percent dropped to 2.8 percent. From figure 4 it is seen that this latter value forms a straight line with the rest of the points. Thus the existence of two independent first order reactions is indicated, as follows:

I.

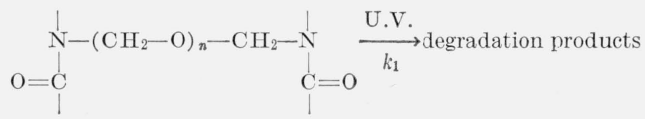

where $n=1$ to 25

II.

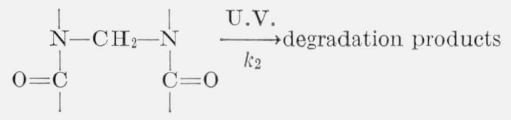

Application of the mathematical expression described above and a least square analysis of the data yields $k_{1}=0.22 \mathrm{hr}^{-1}$ and $k_{2}=0.01 \mathrm{hr}^{-1}$. Here again, reaction I is much faster than reaction II.

The data on polycaprolactam fibers having disulfide type crosslinks are summarized by figure 5 in which the logarithm of percent formaldehyde is plotted against irradiation time. In contrast to the degradation of the methylene-crosslinked fiber and the methylmethoxylated sample, all the points fall on a straight line, indicating only one first order reaction without any apparent other reactions. The rate constant for this reaction is $k=0.025 \mathrm{hr}^{-1}$. 


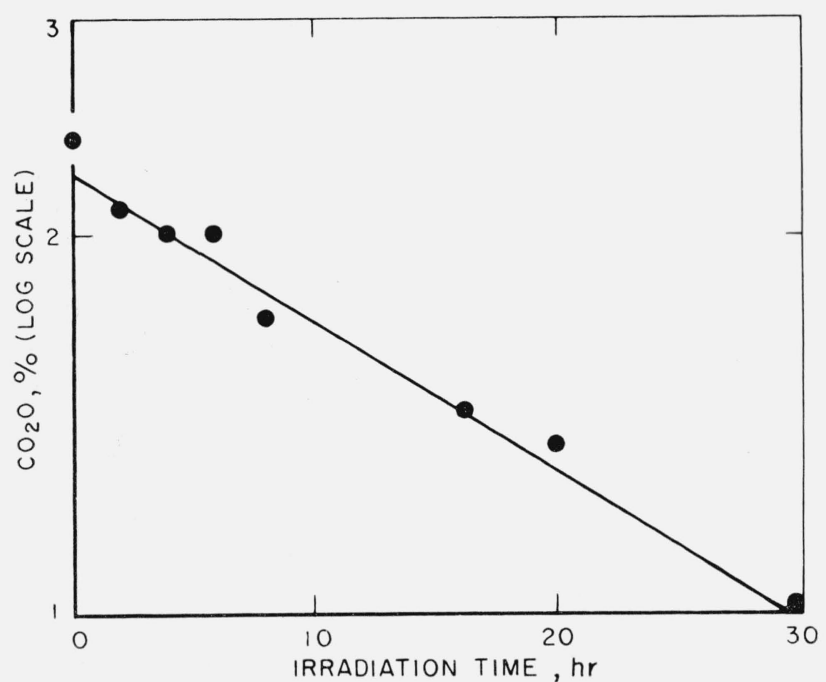

FIGURE 5. Logarithmic plot of the ultraviolet degradation of disulfide-crosstinked polycaprolactam fibers.

Additional evidence for the absence of other independent reactions was obtained from chemical analyses of residual sulfhydryl [12] and methoxyl groups remaining in the sample before and after irradiation. These groups are precursors in the formation of the disulfide crosslinks and could conceivably be present after the formation of these crosslinks. Appreciable amounts of such groups would be expected to follow a degradation pattern distinct from the crosslinks but similar to the degradation of the methylmethoxylated polycaprolactam samples shown earlier. Chemical analysis of the disulfide crosslinked samples (before and after irradiation) however, showed less than 0.3 weight percent methoxyl groups and less than 35 equivalents of free sulfhydryl groups per $10^{6} \mathrm{~g}$ of polymer. These quantities are negligible and are expected to contribute little to the overall degradation of the disulfide crosslinks.

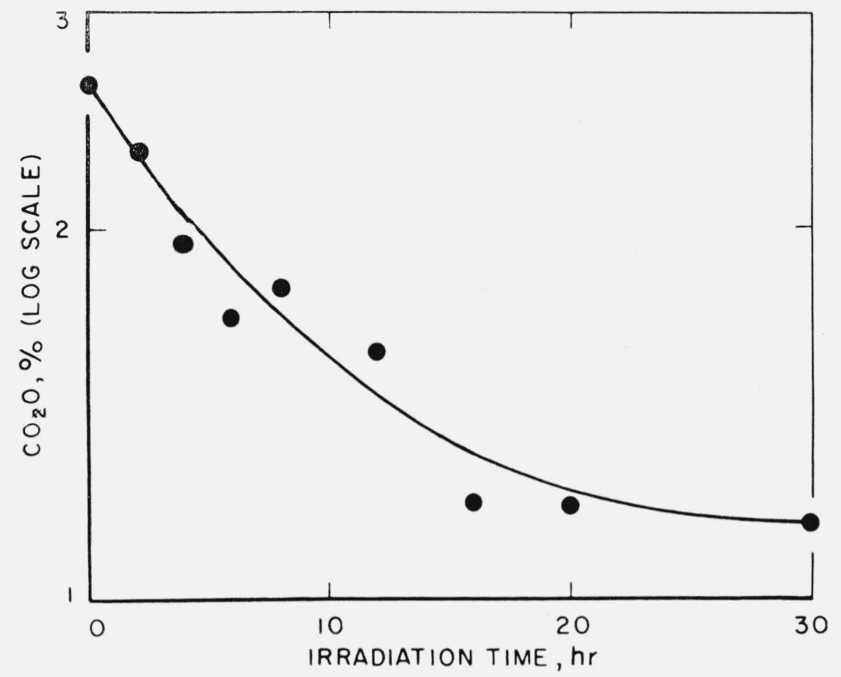

FIGURE 6. Logarithmic plot of the ultraviolet degradation of alkylene sulfide-crosslinked polycaprolactam fibers.
The ultraviolet degradation of polycaprolactam fibers having alkylene sulfide type crosslinks is illustrated by figure 6 . The data are somewhat scattered and could not be analyzed on the basis of two independent first order reactions. Thus the ultraviolet degradation of this sample either does not follow first order kinetics or there are many other independent reactions that obscure interpretation. This latter possibility might indeed be operative inasmuch as the particular chemical reaction series leading to the introduction of the alkylene sulfide crosslinks also forms appreciable amounts of disulfide crosslinks and stabilized sulfhydryl groups [1]. The alkylene sulfide crosslinked fiber thus is expected to contain at least the following groups, all of which will yield various quantities of formaldehyde upon irradiation and subsequent hydrolysis:

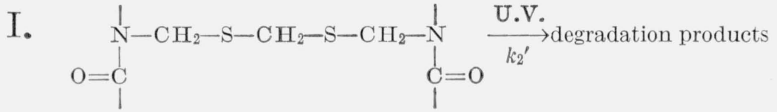

II.

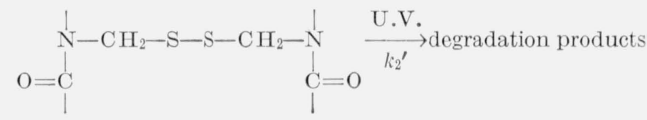

III.

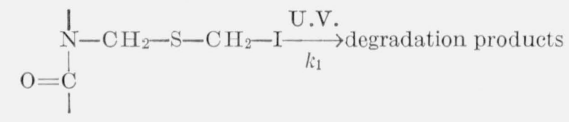

Considering the above factors, other techniques, for example radioactive tracer methods, would have to be applied in an attempt to separate the contributions of the above structures to the overall ultraviolet degradation process. However, it is interesting that, assuming the applicability of two first order reactions as in the other cases, a least square analysis of the data yields a rate constant of $k_{1}=0.18-0.21$ $\mathrm{hr}^{-1}$ that could probably represent the degradation of the stabilized sulfhydryl groups (reaction III).

The overall kinetic results are summarized in table 3 . The data indicate that the values for $k_{1}$ (indicative of the degradation of secondary products) are between 0.18 and $0.22 \mathrm{hr}^{-1}$ in all cases. The value for $k_{2}$ is $0.01 \mathrm{hr}^{-1}$ for the degradation of both the methylmethoxylated and the methylene-crosslinked samples, indicating that in both cases the rate determining step is the scission of the $\mathrm{N}-\mathrm{C}$ bond in the crosslinked part of the network.

TABLE 3. Rate constants for the ultraviolet degradation of chemically modified polycaprolactam fibers

\begin{tabular}{|c|c|c|c|}
\hline Sample & $k_{1}\left(\mathrm{hr}^{-1}\right)$ & $k_{2}\left(\mathrm{hr}^{-1}\right)$ & $k_{2}^{\prime}\left(\mathrm{hr}^{-1}\right)$ \\
\hline $\mathrm{N}-\mathrm{CH}_{2}-\mathrm{O}-\mathrm{CH}_{3}$ & 0.18 & 0.01 & \\
\hline$\underset{\mathrm{N}}{\mathrm{N}}-\mathrm{CH}_{2}-\mathrm{N}$ & .22 & .01 & \\
\hline$\underset{\mid}{\mathrm{N}}-\mathrm{CH}_{2}-\mathrm{S}-\mathrm{S}-\mathrm{CH}_{2}-\mathrm{N}$ & & .025 & \\
\hline $\mathrm{N}-\mathrm{CH}_{2}-\mathrm{S}-\mathrm{CH}_{2}-\mathrm{S}-\mathrm{CH}_{2}-\stackrel{+}{\mathrm{N}}$ & $.18-0.21$ & & $0-0.005$ \\
\hline
\end{tabular}


In the case of the disulfide crosslinked fibers, there is only one rate constant, with a value of 0.025 $\mathrm{hr}^{-1}$, and there are no apparent side reactions.

Finally, in the case of the alkylene sulfide samples, the $k_{2}^{\prime}$ value (indicating the combined degradation of the alkvlene sulfide and disulfide crosslinks) could not reliably be determined due to the heterogeneous nature of the fiber. However, assuming the existence of first order reactions, the $k_{2}^{\prime}$ value would be $0-0.005 \mathrm{hr}^{-1}$.

From chemical analysis of formaldehyde the number of equivalents of crosslinks present before and after irradiation can also be estimated by converting the crosslinks remaining after irradiation to formaldehyde. The results are summarized in table 4 . The data indicate that after $30 \mathrm{hr}$ of irradiation the crosslinking density in the fibers decreased for the methylene-crosslinked sample by 32 percent; alkylene sulfide crosslinked sample (containing appreciable amounts of disulfide crosslinks) by 55 percent; and disulfide crosslinked sample by 58 percent. From

TABLE 4. Relative sensitivity of crosslinked polycaprolactam fibers towards ultraviolet irradiation

\begin{tabular}{|c|c|c|c|}
\hline Sample & $\begin{array}{c}\text { Irradia- } \\
\text { tion }\end{array}$ & $\begin{array}{l}\text { Formal- } \\
\text { dehyde }\end{array}$ & $\begin{array}{l}\text { Cross- } \\
\text { links }\end{array}$ \\
\hline $\mathrm{N}-\mathrm{CH}_{2}-\mathrm{N}$ & $\begin{array}{c}h r \\
\mathrm{a} 0\end{array}$ & $\begin{array}{r}\% \\
3.0\end{array}$ & $\begin{array}{c}\text { equiv. } / 10^{6} g \\
1,000\end{array}$ \\
\hline$"$ & 30 & 2.1 & 682 \\
\hline $\mathrm{N}-\mathrm{CH}_{2}-\mathrm{S}-\mathrm{S}-\mathrm{CH}_{2}-\mathrm{N}$ & 0 & 2.4 & 392 \\
\hline$"$ & 30 & 1.0 & 167 \\
\hline $\mathrm{N}-\mathrm{CH}_{2}-\mathrm{S}-\mathrm{CH}_{2}-\mathrm{S}-\mathrm{CH}_{2}-\mathrm{N}$ & 0 & 2.6 & 288 \\
\hline " & 30 & 1. 2 & 128 \\
\hline
\end{tabular}

s Heated at $170^{\circ} \mathrm{C}$ for $8 \mathrm{~min}$.

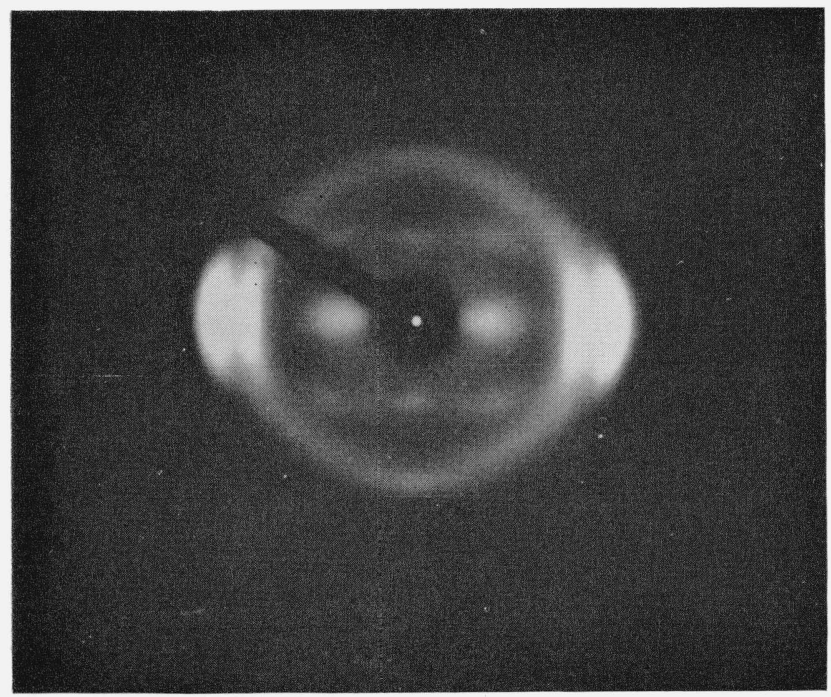

A these results and from the calculated rate constants it is apparent that stability of the disulfide crosslinks is less $\left(k_{2}=0.025 \mathrm{hr}^{-1}\right)$ than either the methylmethoxylated $\left(k_{2}=0.01 \mathrm{hr}^{-1}\right)$, methylene crosslinked $\left(k_{2}=\right.$ $\left.0.01 \mathrm{hr}^{-1}\right)$, or alkylene sulfide crosslinked $\left(k_{2}^{\prime}\right.$ probably less than $0.01 \mathrm{hr}^{-1}$ ) fibers. This behavior of the disulfide crosslinks is not surprising in view of the well-known sensitivity of these groups to radiation damage.

A final observation of considerable interest is the decrease in the internal orientation of the crosslinked systems that apparently accompanies the ultraviolet degradation process. This is indicated by X-ray diffraction photographs as shown in figure 7 .

Figure $7 \mathrm{~A}$ represents the diffraction pattern of an alkylene sulfide crosslinked fiber before irradiation, whereas figure $7 \mathrm{~B}$ shows the diffraction pattern of the same sample after $30 \mathrm{hr}$ of irradiation. A similar relationship was observed for disulfide crosslinked and methylene crosslinked fibers, respectively. In all cases the broadening of the diffraction arcs after irradiation indicates a decrease in orientation. This phenomenon is attributed to a decrease in the internal stress in the network as a result of the scission of the crosslinks upon irradiation. Further work will have to be carried out to quantitatively measure this phenomenon.

The author thanks Mrs. Sally S. Flores, Donald A. Becker, and Sylvia M. Bailey for technical assistance in various phases of this work. Thanks are also due to H. Steffen Peiser for discussions on the X-ray diffraction patterns, Boris Paretzkin for the X-ray exposures, and to Frank L. McCrackin for the computer programing of the kinetic data.

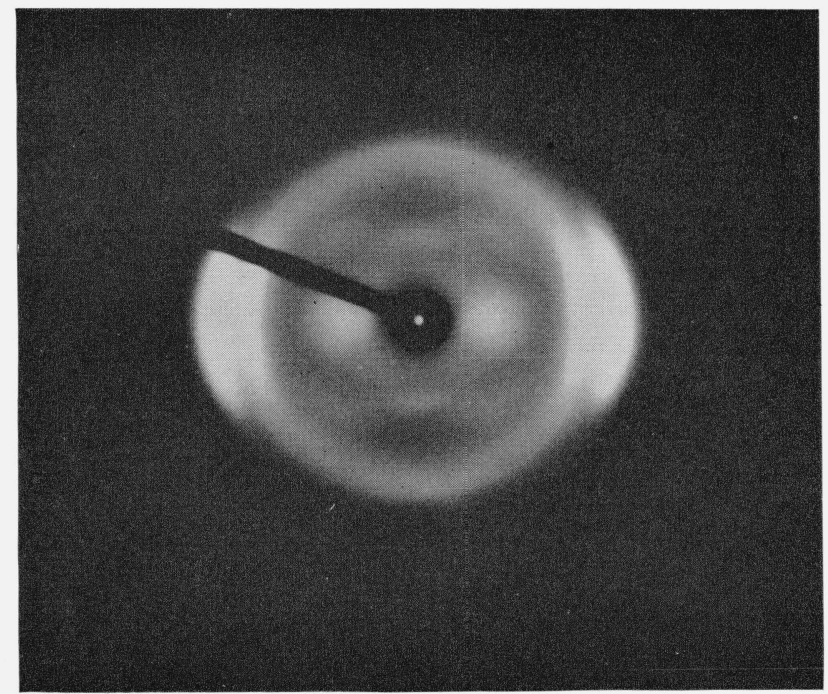

B

FiguRE 7. X-ray diffraction photographs of alkylene sulfide-crosslinked polycaprolactam fibers before $(A)$ and after $(B)$ irradiation. 


\section{References}

[1] S. D. Bruck, J. Research NBS $66 \mathbf{A}$ (Phys. and Chem.), No. 1, 77 (Jan.-Feb. 1962).

[2] S. D. Bruck, J. Research NBS 65A (Phys. and Chem.), No. 6, 489 (Nov.-Dec. 1961)

[3] NBS Tech. News Bul. 45, 152 (1961).

[4] Chemical and Engineering News, "Cross-links crimp and coil Nylon-6 Fiber," pp. 50-51, October 23, 1961.

[5] S. D. Bruck, J. Research NBS 66A (Phys. and Chem.), No. 3, 251 (May-June 1962).

[6] S. D. Bruck, Paper No. 38, Abstract of Papers, Division of Analytical Chemistry, 141st Meeting, American Chemical Society, Washington, D.C., March 21-29, 1962 .
[7] S. D. Bruck, J. Polymer Sci. 55, S29 (1961).

[8] S. D. Bruck, J. Research NBS 65A (Phys. and Chem.), No. 6, 485 (Nov-Dec. 1961)

[9] A. Steyermark, Quantitative Organic Microanalysis, p. 431 (Academic Press Inc., New York, 1961).

[10] W. R. Sorenson and T. W. Campbell, Preparative Methods of Polymer Chemistry, p. 64 (Interscience Publ., Inc., New York, 1961).

[11] B. Graham and O. E. Schupp, Jr., U.S. Patent 2,540,726 Example 1

[12] S. D. Bruck and S. M. Bailey, J. Research NBS 66A (Phys. and Chem.), No. 2, 185 (March-April 1962).

(Paper 66A6-184) 